Submitted: 30 November, 2005

Ref: MS05-17

EHD-D-08-00219 (online submission) for revised paper; 10 October 2008

Accepted: 14 October 2008

\title{
A comparison of Executive Function in very preterm and term infants at eight month corrected age
}

\section{Authors:}

Jing Sun, $\mathrm{PhD}$

School of Public Health

Griffith University, Logan Campus,

Meadowbrook, Q4131

Australia

Heather Mohay, PhD

School of Psychology and Counselling

Queensland University of Technology, Carseldine, Australia Q4034

Michael O'Callaghan, MBBS, FRACP

Mater Children's Hospital, South Brisbane Australia Q4101

\section{Address for correspondence:}

Dr. Jing Sun

Lecturer

School of Public Health,

Griffith University, Logan Campus

Meadowbrook, Q4131

Australia

Tel. +61 7 33821198; Fax. +61 733821034

Email: j.sun@griffith.edu.au; jingsun@optusnet.com.au

Key words: executive function, very preterm infants, working memory, inhibition, planning.

Acknowledgement: The first author received financial support from an Australian International Postgraduate Research Scholarship and from the School of Early Childhood at the Queensland University of Technology. The authors also wish to acknowledge the support of the Growth and Development team at the Mater Children's Hospital, Brisbane. 
Running head: Executive Function

\title{
A comparison of Executive Function in very preterm and term infants at eight month corrected age
}

\begin{abstract}
Background: Executive function (EF) emerges in infancy and continues to develop throughout childhood. Executive dysfunction is believed to contribute to learning and attention problems in children at school age. Children born very preterm are more prone to these problems than their full-term peers.

Aim: To compare EF in very preterm and full-term infants at 8 months after expected date of delivery.

Subjects: 37 very preterm infants without identified disabilities, and 74 gender and age matched healthy full-term infants. The very preterm infants were all $\leq 32$ weeks gestation and $<1250$ grams birthweight.

Outcome measures: EF tasks which measured working memory, inhibition of distraction, and planning at 8 months after expected date of delivery.

Results: The very preterm infants performed significantly more poorly than the full-term infants on all measures of executive function. No significant differences were found between very preterm and full-term infants on any of potentially confounding variables of, infant temperament, maternal education, family income and maternal psychological wellbeing. Very preterm infants had significantly lower scores on the Mental Development Index (MDI) and Psychomotor Development Index (PDI) on the Bayley Scales of Infant Development (BSID II), however when this was partialled out the differences in EF scores remained. Medical complications, lower birthweight and lower gestation age were all found to adversely affect the performance of very preterm infants on executive function tasks.

Conclusion: Very preterm infants performed more poorly than full term infants on measures of EF. Further follow up studies are required to investigate whether EF measures in infancy can predict learning and attention outcome at school age.
\end{abstract}




\section{Introduction}

Advances in medical technologies have resulted in the increased survival of infants of progressively lower birthweight and shorter gestation. Compared with full-term infants, those born early are at increased risk of subsequent difficulties, in behaviour and learning ${ }^{(1)}$. The risk of these adverse outcomes increases as gestation age and birthweight decrease ${ }^{(2)}$.

Executive function (EF) deficits have been linked to a range of problems, including attention deficit disorder (ADD), learning difficulties, and autism ${ }^{(3)}$, all of which are more prevalent in children born preterm ${ }^{(4)}$. EF encompasses goal directed behaviour that is deliberate, conscious, and purposeful ${ }^{(5)}$. Whilst dependent upon basic cognitive processes, such as perception and memory, the behaviours and processes referred to as EF are associated with higher-order cognitive abilities, that require holding plans or programs in mind until executed (working memory), inhibiting irrelevant action (inhibition), and planning a sequence of actions (planning) ${ }^{(3,6)}$. These components of EF have been identified in factor analytic studies ${ }^{\text {(e.g., } 7,8)}$ as well as studies of patients with frontal lobe lesions ${ }^{\text {(e.g., 9). }}$.

Preschool and school aged children who were born preterm have been found to have poorer performance on various tasks measuring EF than their full-term peers ${ }^{(10,11)}$ with those preterm children who had medical complications in the perinatal period being more impaired on EF measures than other preterm children ${ }^{(12)}$.

It is generally agreed that EF is primarily governed by the prefrontal cortex of the brain (13) and the emergence of EF abilities coincides with the development of this part of the brain ${ }^{(14)}$. However as the prefrontal cortex is late to mature and develops rapidly in infancy, it may be particularly vulnerable to disturbance in preterm infants. For example, disruption of 
pathways in the prefrontal lobe may occur because of damage to other neural circuits that connect to the frontal lobes and are therefore implicated in EF development ${ }^{(15)}$.

During the first year of life, significant development of EF takes place. A study of working memory in infants from 8 to 12 months of age, showed that on the $A B$ task (see description of the $A B$ task below in section 2.3) the time delay between hiding the object and allowing the infant to retrieve it could be significantly increased as the child got older without incurring increased errors ${ }^{(16)}$. At a similar age infants have also been shown to begin to inhibit irrelevant responses ${ }^{(17)}$, to become planful, and to be able to carry out relatively complex sequences of goal directed behaviour ${ }^{(18)}$. It has been suggested that any deviation in the development of EF during this critical period may result in enduring learning, attention or behavioural problems ${ }^{(12,19)}$.

Most previous studies of cognitive development in preterm infants have relied upon either the use of standard developmental assessments ${ }^{(20)}$ which are poor predictors of later learning and behaviour ${ }^{(4)}$, or the use of sophisticated technology to assess perception, memory or attention ${ }^{(21,22)}$. The present research used practical and simple measures of EF that could be applied easily in clinics or field settings. It has been argued that the $A B$ task measures working memory and inhibition ${ }^{(23)}$ and that tasks which require the execution of a series of steps to achieve a goal measure planning ${ }^{(24)}$. Therefore these were the assessment tools of choice for comparing the performance of very preterm infants (who are known to have a high risk for learning and attentional problems) and full term infants (who have a much lower risk for these difficulties). It was hypothesised that differences on measures of EF would exist between the two groups, even when the influence of confounding variables were taken into account. If this is the case these measures of specific cognitive abilities, 
which are associated with behaviour and learning, may provide a means of identifying children at risk of school difficulties at an early age.

\section{Method}

\subsection{Subjects}

Both very preterm and full-term infants enrolled in the study were healthy, had no diagnosed disabilities, lived within a 50-kilometre radius of the Mater Mothers' Hospital, and came from English speaking families. All the very preterm infants were born at the Mater Mothers' Hospital, Brisbane, between May 1998 and July 1999, with gestational ages of $\leq 32$ weeks and birthweights of $<1250$ grams. They were recruited into the study by the clinic coordinator when they attended for their routine follow-up assessment at the Growth and Development Clinic at the Mater Children's Hospital, at 8 months corrected age. As not all infants kept their appointment the sample must be viewed as a convenience sample. A total of 37 very preterm infants comprised the study group. Names and addresses of potential fullterm comparison infants who were the same sex as their matched very preterm infant, and born at the Mater Hospital on the same expected date of delivery, were obtained from the hospital's medical records. A letter was sent to each of these families inviting them to participate in the study and infants were enrolled on a first come basis. In order to increase the statistical power of the data analysis two full term infants were matched to each very preterm infant. There were therefore a total of 74 full-term infants all of whom had a birthweight $>2500$ g, gestational age $>37$ weeks and no medical complications in the perinatal period. All infants recruited into the study were tested at eight months $(+$ or -2 weeks) after expected date of delivery. Participant characteristics are presented in Table 1.

Participation in the study was voluntary and informed consent was obtained from at least one parent of each child. Ethical approval for the project was obtained from the Mater 
Children's (Ref No 146C) and Mater Mothers' (Ref No 146M) Hospital Ethics Committees, and the Queensland University of Technology Research Ethics Committee (Ref No QUT $1558 \mathrm{H})$.

Insert Table 1

\subsection{Study design}

A modified A-not-B $(A B)$ task ${ }^{(16)}$ with increasing periods of delay from 2 to $10 \mathrm{~s}$ between hiding the object and retrieval was used to measure both working memory and inhibition to distraction. A planning task, based on the work of Willatts et al. ${ }^{(25,26)}$, which required one, two, or three steps to attain the goal was designed to measure planning.

Infant temperament, maternal education, family income, and maternal psychological wellbeing, have previously been shown to influence infant development ${ }^{(27-29)}$ and may therefore also influence performance on measures of EF. These factors were therefore included in the study design as potential confounding variables. Although most studies of older children and adults have suggested that EF is independent of measures of intelligence $(30,31)$, the Bayley Scales of Infant Development II (BSID II) ${ }^{(32)}$ was also included in the study design as it was felt that abilities measured on this test, such as language and fine motor skills, might influence performance on EF measures.

The influence of perinatal medical complication, lower birthweight, and lower gestation age on the performance of very preterm infants on EF tasks was also examined.

\subsection{Measurement}




\section{Infant working memory and inhibition task (Modified $\mathrm{A} B$ task)}

The $A B$ task has been widely used to measure infant working memory. In this task, an infant sits in front of two identical hiding locations (e.g., cloth covers, cups or wells) that are separated by a small distance. While the infant watches, a desired object is hidden in one location, location A. After a delay, the infant is allowed to reach and search for the object. This hiding and searching at location $\mathrm{A}$ is repeated until the child responds correctly on at least two consecutive trials. Then while the infant watches, the object is hidden at the second location, location B. After a delay, the infant is allowed to reach and search for the object. Infants frequently make the error of searching again at location A, committing what is known as the classic $A B$ error. This is said to demonstrate an inability to inhibit a prepotent response In order to retrieve the goal object the infant must have a mental representation of the object (object permanence) working memory for the location of the object, the ability to inhibit distraction from the occluder (eg a cup) and, when a new hiding location follows a previous correct response, the ability to inhibit the prepotent (previous correct) response.

The infant working memory and inhibition task used in the present study was based on the $A B$ task with cups used as the hiding places. The degree of difficulty of the task was manipulated by increasing the number of potential hiding places (task level) and increasing the delay between hiding the object and being allowed to retrieve it. There were three task levels; 1-cup, 2-cup, and 3-cup tasks. The materials used were 6 plastic cups with handles (1 yellow cup, 2 red cups, and 3 blue cups) which acted as occluders and 3 small round toys. On each trial a toy was hidden beneath the appropriate cup whilst the infant watched. The cups were held for the period of delay and then pushed towards the infant as the examiner said "Find the toy (baby's name) find the toy". 
The 1-cup task was used to familiarize the infants with the task and to ensure that they had object permanence and were able to lift the cup and retrieve the object. All infants were able to demonstrate these abilities. There were three levels of delay on the 1-cup task, 0, 4 and $10 \mathrm{~s}$. with three trials at each level. Inhibition of distraction from the cup was measured on this task

On the 2 and 3-cup tasks there were four levels of delay $(0,2,4$ and $10 \mathrm{~s})$ with six trials at each time delay. The trials were presented in a fixed pattern eg the hiding place for the toy was, right, left, left, right, right, left at 0 second delay and left right right left left right at 2 seconds delay and so on. Inhibition of distraction and working memory for location could be scored on every trial, however as the hiding place was changed in a fixed order rather than only following a correct response it was not possible to score for inhibition of a prepotent response.

All infants were tested on the 1-cup task first starting with 0s delay. On completion of the 10s delay trials or if the child failed the three trials at 4 seconds delay the 2-cup task was administered starting with the 0 s time delay. When the infant completed all trials on the 2cup task or failed to reach to the appropriate cup on three consecutive trials at any time delay the task shifted to the 3-cup task starting at 0s delay. Therefore all infants attempted at least six trials on the 1- cup task and at least 3 trials on the 2- and 3-cup tasks. Testing was terminated when the infant completed all trials on the 3 cup task or failed 3 consecutive trials.

For working memory a score of 1 was awarded each time the infant reached to the correct location and retrieved the toy on the 2- and 3-cup task. As the maximum number of trails was 48 the possible range of scores was $0-48$. 
The distraction score was based on the infant's ability to inhibit distraction by an irrelevant stimulus (viz., the cup that covered the toy). Inability to inhibit distraction was scored on the 1,2, and 3-cup tasks on trials when the infant reached to the cup where the toy was hidden but then played with the cup for more than $2 \mathrm{~s}$ rather than retrieving the goal object. A score of 1 was given each time this occurred. This was then transformed into a proportional score by dividing the total distraction score by the total number of trials when the child reached to the cup where the toy was hidden. High proportional scores indicate inability to inhibit distraction.

\section{Planning Task}

The 1- to 3-step planning tasks used in the current study were based on those used by Willatts and his colleagues ${ }^{(18,25,26)}$ and required the infant to overcome one to three obstacles along the path to the goal.

1-step task. A cloth was placed on the table in front of the infant. An attractive object [toy] was placed on the far end of the cloth such that the child could reach the cloth but could not reach the object. The infant therefore had to pull the cloth in order to retrieve the object.

2-step task. The cloth and goal object were placed in front of the infant as in the 1-step task in addition a transparent barrier was placed between the front of the cloth and the infant so that the infant had to remove the barrier before pulling the cloth to retrieve the object. Using a transparent barrier ensured that the goal object was visible at all times.

3-step task. The barrier, and cloth and were placed in front of the infant as in the 2-step task, however the goal object was placed behind the cloth and a string attached to it was put on the cloth out of the infant's reach. Thus to attain the toy the infant had to remove 
the barrier, pull the cloth to bring the string into reach, and then pull the string to get the toy.

Three trials were given at each level of the task. The time limit for all trials was 30 seconds starting from the child's first contact with the cloth (1-step task) or the barrier (2 and 3-step tasks). These time limits were selected on the basis of data presented by Willatts et al. $(25,26)$. The inter-trial interval was 20 seconds during which the infant was allowed to play with a toy while the next trial was prepared. The goal toys were changed from trial to trial.

If the infant obtained the toy within the time limits on at least one of the three trials at a particular level, testing continued to the next level of the task. If pulling the cloth resulted in the toy falling off the edge of the table another trial was given. If the infant failed to obtain the toy, or the time limit elapsed, on all three trials at a particular level, testing was terminated and this was assumed to represent the ceiling of the child's abilities.

The scoring scheme for the planning task was also adapted from Willatts et al. ${ }^{(18,25,26)}$ and was based on the intentionality of the infant's actions on each component of the task.

For example for the 1-step task (i.e., pulling a cloth to bring the toy within reach), scoring was based on evidence of intent with regards to the infant's (a) behaviour with the cloth; (b) fixation on the toy; and (c) behaviour with the toy. Each of these behaviours was scores as "no intent" "possible intent" or "fully intentional". At each level of the task (i.e., 1step, 2-step and 3-step), a trial on which all components were scored as "fully intentional" was given a score of 1 . Hence the range of possible scores was 0-9.

\section{Other measures}

The Bayley Scales of Infant Development (BS1D II) ${ }^{(32)}$ were used to provide a standard measure of infant development. The mental development scale includes items that assess 
memory, habituation, vocalization, language and social skills and the psychomotor development scale assesses the ability to control the gross and fine muscle groups. A mean and standard deviation for Mental Development Index (MDI) and Psychomotor Development Index (PDI) are 100 and 15 respectively.

The Australian revised version of the Infant Temperament Questionnaire ${ }^{(33)}$ was used to assess infant temperament. This is a 30 -item questionnaire on which parents rate various aspects of the child's behaviour on a six-point rating scale from almost never (score 1) to almost always (score 6). Infant temperament was classified as easy, average, or difficult based on the norms for Australian children provided by Sanson et al. ${ }^{(31)}$.

Maternal psychological wellbeing was measured by the General Health Questionnaire (GHQ) ${ }^{(34)}$, which provides a measure of maternal symptoms of anxiety and depression. Mothers scoring 13 or more were regarded as having signs of anxiety and depression whilst those with lower scores were regarded as having normal psychological status.

Maternal education and family income, were recorded from the demographic information sheet completed by parents.

Infant perinatal information was obtained from medical records at the Mater Mother's hospital. These included birth weight, gestational age, interuterine growth retardation, and the following medical complications; home oxygen dependency (HOME O2), [defined as continuing to need supplemental oxygen at home following hospital discharge] ventricular dilatation (VD), periventricular leukomalacia (PVL), and cerebro-ventricular haemorrhage $(\mathrm{CVH})$. For the purpose of this study a "high medical risk" very preterm infant was defined as a very preterm infant who had one or more of these medical complications.

\subsection{Procedure for the Assessment}


All infants were tested individually in a quiet testing room located in the Department of Child Health at the Mater Children's Hospital, Brisbane. Infants sat on their mothers' lap adjacent to one side of the testing table and facing the video camera. The table was rectangular $(90 \mathrm{~cm} \times 75 \mathrm{~cm})$ and covered with a white sheet. The examiner sat at 90 degrees to the infant so as not to obscure the view of the video camera. Infants and their mothers were videotaped during the EF tasks and these videotapes were later used to check scoring and for reliability studies.

Testing commenced following a brief familiarization period during which the experimenter explained the test procedures to the mother and played with the infant.

The tasks were presented in a fixed order: Infant working memory and inhibition task, planning task, and Bayley Scales of Infant Development (BSID II). Following these assessments, the mothers were asked to complete the demographic information sheet, GHQ, and Infant Temperament Questionnaire. The assessment session lasted for an average of 40 minutes including time for the mothers to complete the questionnaires. If the babies became distressed or disinterested they were given a break and fed or changed if need be. No infants failed to complete the testing session.

The first author administered and scored all infant assessments. Another trained coder scored 10 percent of the infant working memory, inhibition of distraction and planning tasks from the videotaped records. There was a high percentage of agreement in coding working memory (99\%), inability to inhibit distraction from external stimuli (93\%) and planning trials with full intention (95\%).

\subsection{Statistical analysis}


All data were analysed using SPSS version 13.0. The very preterm and full term infants were compared on measures of infant general development, infant temperament, SES, maternal education and maternal wellbeing using Chi-square for categorical variable and one-way ANOVA for continuous variables (See Table 2). Where significant differences were found between the very preterm and full-term infants these variables were regarded as confounding variables which might contribute to the difference in EF scores between very preterm and full-term infants. Therefore after EF scores for very preterm and term infants had been examined using an ANOVA analyses, confounding variables were entered as covariates in an ANCOVA analysis to partial out any effect which they had on the difference between very preterm and full term infants on EF measures.

Medical complications, birthweight, and gestation age have previously been shown to influence the development of very preterm infants ${ }^{(2,35)}$. The effects of these variables on performance on EF tasks were therefore examined by dividing the very preterm infants into a low and a high risk group for each variable and comparing the EF scores of these groups with each other and with the full term group using ANOVA analysis with a Bonferroni test.

\section{Results}

Table 2 show the results of ANOVAs and Chi-squares to examine differences between preterm and full term infants on potential confounding variables.

Insert Table 2

Very preterm infants had significantly lower scores than full-term infants on the psychomotor development scale (PDI) of the BSID II but no significant differences were found between the groups on the mental development scale (MDI) or any of the other 
variables. Analysis of variance (ANOVA) (unadjusted model) was firstly used to compare very preterm infants to full-term infants on the performance of EF tasks (see Table 3). Bayley PDI were entered as a covariate in an analysis of co-variance (ANCOVA) model (adjusted model) to examine their effect on the differences between very preterm and full-term infants on EF measures (see Table 3).

Insert Table 3

Significant differences between the very preterm infants and the full-term infants were found on the EF measures and these differences remained even when PDI was taken into consideration.

It is possible that adverse perinatal factors affected performance on EF tasks more than prematurity per se. This was examined by dividing the very preterm group into lower and higher risk groups on the basis of, medical complications, birthweight and gestational age and comparing each high and low risk group with each other and with the full term infant group on measures of EF using an ANOVA with Bonferroni tests. The results of their analyses are shown in Tables 4,5 , and 6.

Insert Table 4

Insert Table 5 
Insert Table 6

No statistically significant differences were found between the low risk and high risk very preterm groups on any measures of EF although the low risk group consistently out performed the high risk group. Both groups consistently obtained scores which were inferior to those of the full term infant group on all measures of EF. The differences between the high risk very preterm groups and the full term infants reached statistical significance in all instances except in the case of the very low gestational age group on measures of inhibition of distraction. However the differences between the low risk very preterm groups and the full term infant group did not always reach statistical significance suggesting that prematurity per se may not affect some aspects of cognitive development.

\section{Discussion}

The present study found that at 8 months corrected age the performance of very preterm infants was inferior to that of full-term infants on EF tasks of working memory, inhibition to distraction, and planning. These findings reinforce the call from a number of researchers for the measurement of more specific cognitive abilities when assessing the development of very preterm infants ${ }^{(36)}$. Furthermore as very preterm infants performed more poorly than full term infants on measures of EF and as deficits in these abilities have been linked to later learning and attentional problems, to which very preterm infants are more prone, it is possible that such measures may provide a means of early detection of learning and behavioural problems. Follow up studies at school age are required to confirm this. 
Infant temperament in very preterm infants did not differ from full-term infants. These findings are consistent with those reported in the Australian Temperament study ${ }^{(37)}$. However it is possible that the number of very preterm infants with a "difficult" temperament was reduced because infants with identified disabilities were excluded from the study. Maternal educational level, family income, and maternal psychological status also did not differ for the very preterm infants and full-term infants. No difference was found between The Bayley scale MDI scores for preterm and full term infants, and both groups had mean scores which were above the test mean. This is inconsistent with the findings of previous studies ${ }^{(4,38-40)}$ most of which have reported a significantly below average developmental quotient for preterm infants. Most of these studies have been with older infants and children and they have not used the BSDI II. The current atypical results may be attributable to the scoring system and norms for this test they do however suggest that the subject sample was biased towards higher functioning infants. In keeping with other studies ${ }^{(41)}$ PDI scores on the BSID II were significantly lower for very preterm infants than for full-term infants. It is possible that children with poor fine motor skills may have difficulty executing reaching and grasping in the executive function tasks. However when PDI was controlled for, the differences between very preterm and full-term infants on measures of EF remained.

Although very premature birth seemed to adversely affect EF, those infants with higher perinatal risk factors such as a birthweight $<1000$ g or gestational age $<28$ wks or serious medical complications performed more poorly than larger more mature very preterm infants and those who had a relatively uncomplicated perinatal course. Given the small number of subjects these findings must be interpreted with caution. However to date this is the only study which has compared high risk and low risk preterm infants in terms of the development of a range of EF abilities in infancy. Previous studies have also reported that perinatal risk factors influence cognitive development however these have typically examined EF in older 
children and compared the development of children born preterm to that of children born full term $^{(12)}$, or have examined only a limited range of EF abilities during the first year of life ${ }^{(42)}$.

There is considerable evidence that tasks which require the holding of information in memory involve the dorsolateral and ventro-lateral prefrontal cortex ${ }^{(30)}$. Tasks that require planning a sequence of steps are also regulated by the dorsolateral prefrontal cortex ${ }^{(31)}$. The deficits in all measures of EF observed in preterm infants, particularly in those with higher perinatal risk, may be associated with the adverse effects of premature birth and the related medical complications on the prefrontal cortex which is very immature and sensitive during this period of development ${ }^{(43)}$. Mouradian, Als, and Coster ${ }^{(44)}$ suggested that deficits in EF might be due to late maturing cortical organization, particularly of the prefrontal regions. Myelination of the brain has been demonstrated to occur in a systematic fashion starting at the end of the first trimester and continuing at least until the end of the second year ${ }^{(45)}$. Between 23 and 32 weeks of gestation, structural differentiation of the central nervous system is at its most rapid (i.e., neuronal differentiation, glial cell growth, myelination, axonal and dendritic growth and synapse formation). The very preterm infants in the present study were born between 24 and 32 weeks gestation just at this time of brain development. Most of these very preterm infants were in the NICU for up to three months after they were born. The environment in the NICU is unlikely to be conducive to the development of the brain, and the perinatal risk factors which occurred during this period may further adversely affect brain development. Those very preterm infants who experience adverse perinatal events are at particular risk for abnormal prefrontal cortex functioning, and hence deficits in EF.

Deficits of EF may have long term consequences in terms of learning and behavioural problems at school. Taylor, Klein, et al. ${ }^{(2)}$ suggested that medical risk may influence the 
long term developmental outcomes of very preterm infants and Anderson et al. ${ }^{(10)}$ suggested that this might possibly result in inability to ever acquire aspects of EF. During school years, children born preterm and especially those who experienced high perinatal risks (i.e., high medical risks, extremely low birthweight, shorter gestation) have been found to have higher rates of deficits in cognitive and neuropsychological abilities, attention, mathematics achievement, and adaptive behaviours, as well as higher rates of special education placements compared with their full-term counterparts ${ }^{(12,46)}$. Recent MRI studies of such infants at term suggest strongly that cerebral neuronal structures are frequently abnormal ${ }^{(15)}$. Volpe $^{(15)}$ found that perinatal periventricular leukomalacia or cerebral white matter injury seems to have major deleterious effects on subsequent development of fibre tracts both in the cerebral white matter and more distally. This brain injury may have an impact on subsequent brain development including that of the prefrontal cortex ${ }^{(15)}$. These observations are of particular importance because of the high incidence among survivors of prematurity of subsequent cognitive deficits ${ }^{(15)}$. The prospect of early detection of executive dysfunction raises the possibility of early identification of learning and behavioural problems and hence the development of interventions to mitigate their long term adverse effects. 
Table 1 Characteristics of the very preterm and full-term infant groups

\begin{tabular}{ccc}
\hline Variables & $\begin{array}{c}\text { Preterm infants } \\
(\mathrm{n}=37)\end{array}$ & $\begin{array}{c}\text { Full-term infants } \\
(\mathrm{n}=74)\end{array}$ \\
\hline Birthweight [g] & $1008(246)$ & $3440(328)$ \\
$M(S D)$ & 21 & 0 \\
$<1000 \mathrm{~g}(\mathrm{n})$ & 16 & 0 \\
$1000-1250 \mathrm{~g}(\mathrm{n})$ & & $39(1.1)$ \\
Gestational age [weeks] & $28(1.9)$ & 0 \\
$M(S D)$ & 15 & 0 \\
$<28$ weeks $(n)$ & 22 & $38(51.4)$ \\
$28-32$ weeks $(n)$ & & \\
Sex of Child & $19(51.4)$ & \\
Male $n(\%)$ & & \\
\hline
\end{tabular}


Table 2 Comparison of very preterm and full-term infants on infant and maternal variables

\begin{tabular}{|c|c|c|c|c|}
\hline Variables & $\begin{array}{l}\text { Preterm } \\
(\mathrm{n}=37)\end{array}$ & $\begin{array}{l}\text { Full-term } \\
(\mathrm{n}=74)\end{array}$ & t or $\chi^{2}$ & $p$ \\
\hline Bayley MDI $M(S D)$ & $111.6(5.6)$ & $110.9(6.6)$ & $\mathrm{t}=0.53$ & 0.59 \\
\hline $\begin{array}{l}\text { Bayley PDI } M(S D) \\
\text { Temperament }\end{array}$ & $97.5(13.1)$ & $106.8(8.3)$ & $\mathrm{t}=4.55$ & 0.00 \\
\hline $\begin{array}{l}\text { Easy } \quad \mathrm{n}(\%) \\
\text { Average } \mathrm{n}(\%) \\
\text { Difficult } \mathrm{n}(\%)\end{array}$ & $\begin{array}{l}20(54.1) \\
11(29.7) \\
6(16.2)\end{array}$ & $\begin{array}{l}43(58.1) \\
18(24.3) \\
13(17.6)\end{array}$ & $\chi 2=.94$ & 0.9 \\
\hline \multicolumn{5}{|l|}{ Maternal education } \\
\hline $\begin{array}{l}\mathrm{n}(\%) \leq \text { Grade } 12 \\
\mathrm{n}(\%)>\text { Grade } 12\end{array}$ & $\begin{array}{l}26(78.8) \\
7 \quad(21.2)\end{array}$ & $\begin{array}{l}48(64.9) \\
26(35.1)\end{array}$ & $\chi^{2}=2.1$ & 0.2 \\
\hline \multicolumn{5}{|l|}{ Family income p.a. } \\
\hline $\begin{array}{l}\mathrm{n}(\%) 30,000 \text { and less } \\
\mathrm{n}(\%) 30,001-59,999 \\
\mathrm{n}(\%) 60,000 \text { and } \\
\text { above }\end{array}$ & $\begin{array}{c}13(35.1) \\
19(51.4] \\
5(13.5)\end{array}$ & $\begin{array}{l}16(21.6) \\
41(55.4) \\
17(23.0)\end{array}$ & $\chi 2=0.2$ & 0.2 \\
\hline \multicolumn{5}{|l|}{$\begin{array}{l}\text { Maternal Psychological } \\
\text { wellbeing (GHQ scores) }\end{array}$} \\
\hline $\begin{array}{l}\mathrm{n}(\%) \text { score } \leq 12 \\
\mathrm{n}(\%) \text { score }>12\end{array}$ & $\begin{array}{l}32(86.5) \\
5(13.5)\end{array}$ & $\begin{array}{l}66(89.2) \\
8(10.8)\end{array}$ & $\chi 2=2.4$ & 0.3 \\
\hline
\end{tabular}


Table 3 Executive Function scores for very preterm and full-term infants at eight months corrected age with and without Bayley PDI taken into consideration as a co-variate

\begin{tabular}{|c|c|c|c|c|c|c|}
\hline \multirow[t]{2}{*}{ Executive function } & \multirow{2}{*}{$\begin{array}{l}\text { Preterm } \\
(n=37)\end{array}$} & \multirow{2}{*}{$\begin{array}{l}\text { Full-term group } \\
\qquad(n=74)\end{array}$} & \multicolumn{2}{|c|}{ Unadjusted model } & \multicolumn{2}{|c|}{ Adjusted model } \\
\hline & & & $F$ & $p$ & $F$ & $P$ \\
\hline $\begin{array}{l}\text { 1. Working } \\
\text { memory } \\
M(S D)\end{array}$ & $\begin{array}{l}11.27(6.09) \\
\mathbf{1 2 . 5 9}(\mathbf{1 . 2 6 )}\end{array}$ & 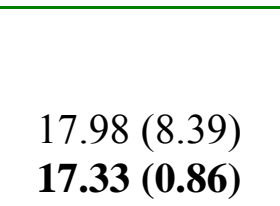 & 18.73 & .00 & 8.88 & 0.00 \\
\hline $\begin{array}{l}\text { 3. Inability to } \\
\text { inhibit distraction } \\
M(S D)\end{array}$ & $\begin{array}{l}0.65(0.31) \\
0.62(0.05)\end{array}$ & $\begin{array}{l}0.39(0.30) \\
\mathbf{0 . 3 7}(\mathbf{0 . 0 4})\end{array}$ & 20.45 & 0.00 & 11.21 & 0.00 \\
\hline $\begin{array}{l}\text { 4. Planning } \\
M(S D)\end{array}$ & $\begin{array}{l}1.54(1.72) \\
1.78(0.36)\end{array}$ & $\begin{array}{l}3.17(2.31) \\
3.05(0.25)\end{array}$ & 14.44 & .00 & 7.56 & 0.01 \\
\hline
\end{tabular}

Notes. Figures in bolds in the table are adjusted means and standard error in an adjusted model when Bayley and PDI were taken into consideration as co-variates 
Table 4 Executive Function scores at 8 months corrected age for very preterm infants at high and low medical risk, and full-term infants.

\begin{tabular}{|c|c|c|c|c|c|c|}
\hline Variables & $\begin{array}{l}\text { High Medical } \\
\text { Risk preterms } \\
\quad(\mathrm{n}=18)\end{array}$ & $\begin{array}{l}\text { Low Medical } \\
\text { Risk preterms } \\
\qquad(\mathrm{n}=19)\end{array}$ & $\begin{array}{l}\text { Full-term Infants } \\
\qquad(\mathrm{n}=74)\end{array}$ & $F$ & pe & Post-hoc test \\
\hline $\begin{array}{l}\text { 1. Working } \\
\text { memory } \\
M(S D) \\
\text { 3. Inability to } \\
\text { inhibit } \\
\text { distraction }\end{array}$ & 9.06 (6.66)A1 & 13.15 (4.97) A2 & 17.98 (8.39) A3 & 10.82 & 0.00 & $\begin{array}{l}\text { A1 vs.A3 }(0.00) \\
\text { A2 vs.A3 }(0.04)\end{array}$ \\
\hline$M(S D)$ & $0.72(0.28)$ B1 & $0.60(0.32) \quad$ B2 & $0.38(0.30) \quad$ B3 & 10.98 & 0.00 & $\begin{array}{l}\text { B1 vs.C3 }(0.00) \\
\text { B2 vs.C3 }(0.01)\end{array}$ \\
\hline $\begin{array}{l}\text { 4. Planning } \\
\qquad M(S D)\end{array}$ & $1.23(1.56) \mathbf{C 1}$ & 1.89 (1.85) C2 & $3.17(2.31) \mathbf{C 3}$ & 7.52 & 0.00 & $\begin{array}{l}\text { C1 vs. } \mathrm{C} 3(0.00) \\
\mathrm{C} 2 \text { vs } \mathrm{C} 3(0.04)\end{array}$ \\
\hline
\end{tabular}

Notes. 1. A1 to $\mathrm{C} 3$ are labels so that comparison between the three groups can be identified.

2. Post-hoc test: Bonferroni test. Only Bonferroni tests showing significant differences are reported. 
Table 5 Executive function scores at eight months corrected age for infants with birthweights $<1000 \mathrm{~g}, 1000-1250 \mathrm{~g}$, and full-term infants

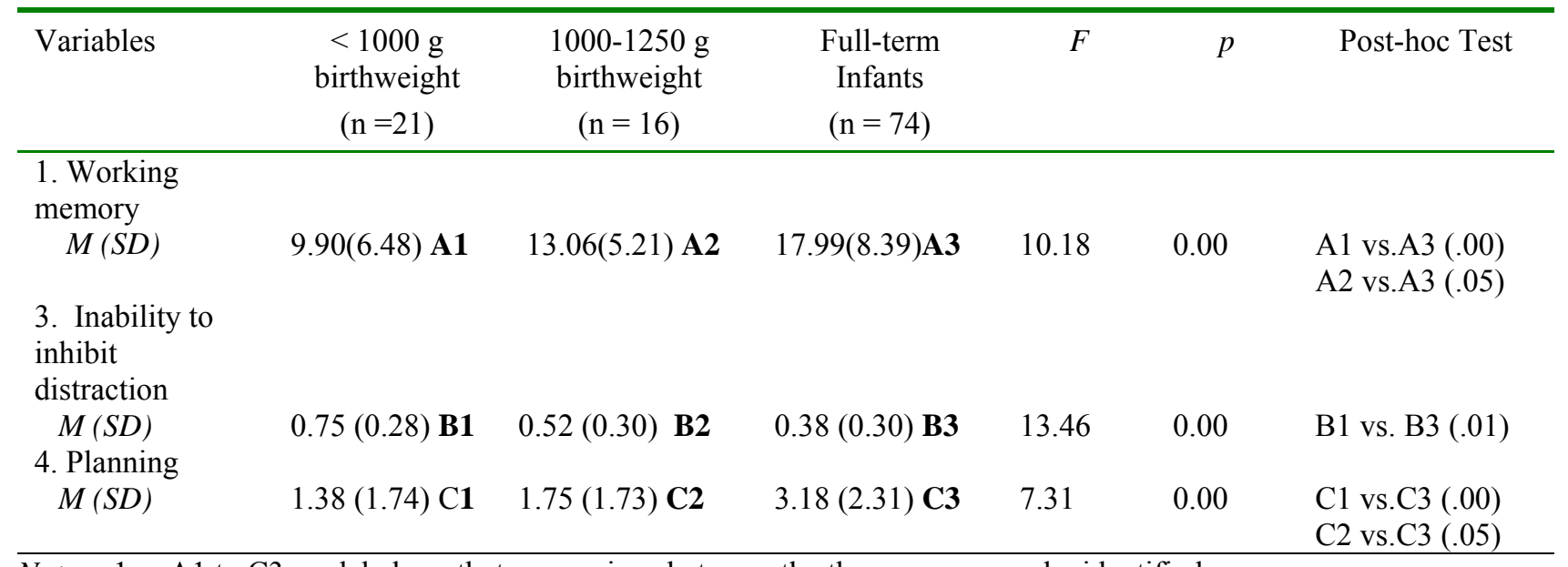

Notes. 1. . A1 to C3 are labels so that comparison between the three groups can be identified.

2. Post-hoc test: Bonferroni test. Only Bonferroni test showing significant differences are reported. 
Table 6 Executive Function scores at eight months corrected age for infants $<28$ weeks gestation, 28-32 weeks gestation, and full term infants

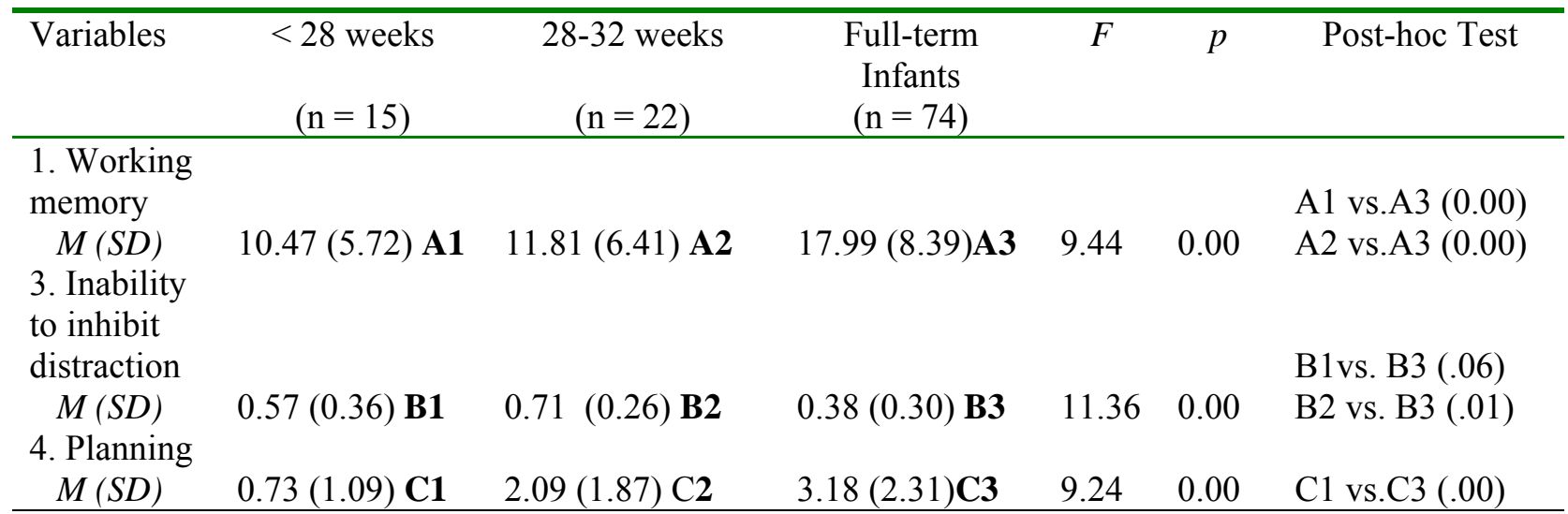

Notes. 1. A1 to $\mathrm{C} 3$ are labels so that comparison between the three groups can be identified.

2. Post-hoc test: Bonferroni test. Only Bonferroni test showing significant differences are reported. 


\section{References}

1. Wolke D, Meyer R. Cognitive status, language attainment, and prereading skills of 6year-old very preterm children and their peers: the Bavarian longitudinal study.

Developmental Medicine and Child Neurology. 1999;41:94-109.

2. Taylor HG, Klein N, Schatschneider C, Hack M. Predictors of early school age outcomes in very low birth weight children. Developmental and Behavioral Pediatrics. 1998;19(4):235-43.

3. Barkley RA. Behavioral inhibition, sustained attention, and executive functions: Constructing a unifying theory of ADHD. Psychological Bulletin. 1997;121(1):65-94. 4. Hack M, Taylor G, Drotar D, Schluchter M, Cartar L, Wilson-Costello D, et al. Poor predictive validity of the Bayley Scales of Infant Development for cognitive function of extremely low birth weight children at school age. Pediatrics. 2005;116(2):333-41.

5. Rabbitt P. Introduction: Methodologies and models in the study of executive function. In: Rabbitt P, editor. Methodology of frontal and executive function. Hove, East Sussex: Psychology Press; 1997. p. 1-38.

6. Fuster JM. The prefrontal cortex: Anatomy, physiology, and neuropsychology of the frontal lobe. New York: Lippincott-Raven; 1997.

7. Levin HS, Fletcher JM, Kufera JA, Harward H, Lilly MA, Mendelsohn D, et al. Dimensions of cognition measured by the Tower of London and other cognitive tasks in head-injured children and adolescents. Developmental Neuropsychology. 1996;12:17-34. 8. Welsh MC, Pennington BF, Groisser DB. A normative-developmental study of executive function: A window on prefrontal function in children. Developmental Neuropsychology. 1991;7(2):131-49. 
9. Stuss DT. Interference effects on memory functions in postleukotomy patients: An attentional perspective. In: Levin HS, Eisenberg HM, Benton AL, editors. Frontal lobe function and dysfunction. New York: Oxford University Press; 1991. p. 157-72.

10. Anderson SW, Damasio H, Tranel D, Damasio AR. Long-term sequelae of prefrontal cortex damage acquired in early childhood. Developmental Neuropsychology. 2000;18(3):281-90.

11. Harvey JM, O'Callaghan MJ, Mohay H. Executive function of children with extremely low birthweight: A case control study. Developmental Medicine and Child Neurology. 1999;41:292-7.

12. Luciana M, Lindeke L, Georgieff M, Mills M, Nelson CA. Neurobehavioral evidence for working-memory deficits in school-aged children with histories of prematurity. Developmental Medicine and Child Neurology. 1999;41:521-33.

13. Hoon A, Melhem ER. Neuroimaging: Applications in disorders of early brain development. Developmental and Behavioral Pediatrics. 2000;21(4):291-302.

14. Diamond A. The development and neural bases of memory functions as indexed by the $A B$ and delayed response tasks in human infants and infant monkeys. The development and neural bases of higher cognitive functions: Annals of the New York Academy of Sciences. New York: The New York Academy of Sciences; 1990. p. 394-433.

15. Volpe JJ. Encephalopathy of Prematurity Includes Neuronal Abnormalities. Pediatrics. 2005;116(1):221 - 5 .

16. Diamond A, Doar B. The performance of human infants on a measure of frontal cortex function, the delayed response task. Developmental Psychobiology. 1989;22(3):27194.

17. Diamond A. Development of the ability to use recall to guide action, as indicated by infants' performance on AB. Child Development. 1985;56:868-83. 
18. Willatts P. Development of means-end behavior in young infants: Pulling a support to retrieve a distant object. Developmental Psychology. 1999;35(3):651-67.

19. Taylor HG, Klein N, Minich NM, Hack M. Middle-school-age outcomes in children with very low birthweight. Child Development. 2000;71:1495-511.

20. Rickards AL, Kelly EA, Doyle LW, Callanan C. Cognition, academic progress, behavior and self-concept at 14 years of very low birth weight children. Developmental and Behavioral Pediatrics. 2001;22(1):11-8.

21. Rose SA, Feldman JF, Wallace IF, McCarton C. Information processing at 1 year: Relation to birth status and developmental outcome during the first 5 years. Developmental Psychology. 1991;27(5):723-37.

22. Fagan JF. The relationship of novelty preferences during infancy to later intelligence and later recognition memory. Intelligence. 1984;8:339-46.

23. Diamond A. Abilities and neural mechanisms underlying AB performance. Child Development. 1988;59:523-7.

24. Willatts P. Development of problem-solving in infancy. In: Slater A, Bremner G, editors. Infant development. Hove, East Sussex: Lawrence Erlbaum; 1989. p. 143-82.

25. Willatts P, Forsyth JS, DiModugno MK, Varma S, Colvin M. Influence of long-chain polyunsaturated fatty acids on infant cognitive function. Lipids. 1998;33(10):973-80.

26. Willatts P, Forsyth JS, DiModugno MK, Varma S, Colvin M. Effect of long-chain polyunsaturated fatty acids in infant formula on problem solving at 10 months of age. The Lancet. 1998;352(August 29):688-91.

27. Landry SH, Denson SE, Swank PR. Effects of medical risk and socioeconomic status on the rate of change in cognitive and social development for low birth weight children. Journal of Clinical and Experimental Neuropsychology. 1997;19(2):261-74. 
28. Murray L, Cooper PJ. The impact of postpartum depression on child development. International Review of Psychiatry. 1996;8(1):55-64.

29. Calkins SD, Fox NA, Marshall TR. Behavioral and physiological antecedents of inhibited and uninhibited behavior. Child Development. 1996;67:523-40.

30. Diamond A, Kirkham N, Amso D. Conditions under which young children can hold two rules in mind and inhibit a prepotent response. Developmental Psychology. 2002;38(3):352-62.

31. Levin HS, Song J, Ewing-Cobbs L, Roberson G. Porteus Maze performance following traumatic brain injury in children. Neuropsychology. 2001;15(4):557-67.

32. Bayley N. Bayley scale of infant development: Manual. 2nd ed. San Antonio, TX: The Psychological Corporation; 1993.

33. Sanson A, Prior M, Garino E, Oberklaid F, Sewell J. The structure of infant temperament: Factor analysis of the revised infant temperament questionnaire. Infant Behavior and Development. 1987;10:97-104.

34. Goldberg D. The general health questionnaire. Windsor, England: NFER-Nelson; 1981.

35. Piecuch RE, Leonard CH, Cooper B, Sehring SA. Outcome of extremely low birth weight infants (500 to 999 grams) over a 12-year period. Pediatrics. 1997;100(4):633-7. 36. Aylward GP. Infant and early childhood neuropsychology. New York: Plenum Press; 1997.

37. Oberklaid F, Prior M, Sanson A. Temperament of pre-term versus full-term infants. Journal of Behavioural Pediatrics. 1986;7:159-62.

38. Escobar GJ, Littenberg B, Petitti DB. Outcome among surviving very low birthweight infants: A meta-analysis. Archives of Disease in Childhood. 1991;66:204-11. 
39. Hack M, Fanaroff AA. Outcomes of children of extremely low birthweight and gestational age in the 1990's. Early Human Development. 1999;53:193-218.

40. Wood N, Marlow N, Costeloe K, Gibson A, Wilkinson A. Neurologic and developmental disabilities after extremely preterm birth. New England Journal of Medicine. 2000;343(4):343:78.

41. Bonin M, Pomerleau A, Malcuit G. A longitudinal study of visual attention and psychomotor development in preterm and full-term infants during the first six months of life. Infant Behavior and Development. 1998;21(1):103-18.

42. Ross G, Tesman J, Auld PM, Nass R. Effects of subependymal and mild intraventricular lesions on visual attention and memory in premature infants. Developmental Psychology. 1992;28(6):1067-74.

43. Diamond A, Lee E. Inability of five-month-old infants to retrieve a contiguous object: A failure of conceptual understanding or of control of action? Child Development. 2000;71(6):1477-94.

44. Mouradian LE, Als H, Coster WJ. Neurobehavioral functioning of healthy preterm infants of varying gestational ages. Developmental and Behavioral Pediatrics. 2000;21(6):408-16.

45. Battin MR, Maalouf EF, Counsell SJ, Herlihy AH, Rutherford MA, Azzopardi D, et al. Magnetic resonance imaging of the brain in very preterm infants: Visualization of the germinal matrix, early myelination, and cortical folding. Pediatrics. 1998;101(6):957-62. 46. Taylor HG, Anselmo M, Foreman AL, Schatschneider C, Angelopoulos J. Utility of kindergarten teacher judgments in identifying early learning problems. Journal of Learning Disabilities. 2000;33(2):200-10. 